\title{
Influence of cerebral embolism on brain monoamines
}

\author{
N. I S H I H A R A, K. M . A . W E L CH, J . S . M EYER, E. CHAB I, \\ H. N A R I T O M I, T-P. F. W A N G, J. H. N E L L, M-C. H S U, \\ A N D Y. M I Y A K A W A \\ From the Baylor-Methodist Center for Cerebrovascular Research, and the Department of Neurology, \\ Baylor College of Medicine, Houston, Texas, USA
}

SUMMARY In baboons the right cerebral hemisphere was embolised by a shower of microemboli, immediately followed by one large embolus designed to occlude the middle cerebral artery (MCA). One hour after embolism a significant, though small, reduction in blood flow and oxygen consumption of the embolised hemisphere was recorded, at which time the animals were killed and brain monoamines measured. Dopamine was reduced in the ipsilateral caudate nucleus, the reported site of maximal ischaemic damage in this model. Dopamine levels were increased in frontal and occipital grey matter sampled from areas surrounding the occluded MCA territory and in similar brain areas of the opposite non-embolised hemisphere. Noradrenaline was increased in grey matter from both cerebral hemispheres, as well as subcortical structures bilaterally. Brain 5-hydroxytryptamine levels were unaltered, but increased 5hydroxyindoleacetic acid in cisternal cerebrospinal fluid suggested transient alteration in 5-hydroxytryptamine metabolism after embolism. The effects of cerebral embolism on brain monoamine metabolism appear to be different from the effects of permanent surgical occlusion of major cerebral vessels. The bilaterality of effects after unilateral hemispheric embolism might be related to diaschisis. The mechanisms of the observed changes, as well as their relevance to the progression of cerebral ischaemia and the complications associated with cerebral embolism, still require to be established.

Disturbance of brain monoamine function has recently assumed increasing importance among the metabolic derangements resulting from cerebral ischaemia. The depletion of brain monoamines, their release into the extraneuronal compartment, and their subsequent accumulation may contribute to number of complications of ischaemia and the progression of brain infarction (Welch et al., 1972, 1973). Disorder of monoamine metabolism has now been demonstrated in a variety of experimental models of cerebral ischaemia. In the baboon, release of 5-hydroxytryptamine (5-HT) from brain into cerebral arteriovenous blood was observed within one minute of surgical occlusion of a major cerebral artery (Welch et al., 1972). Ischaemia produced by unilateral common carotid artery (CCA) occlusion in the gerbil (Zervas et al.,

Address for reprint requests: Dr K. M. A. Welch, Associate Professor, Department of Neurology, Baylor College of Medicine, Neurosensory Center, 6501 Fannin (NB302), Houston, Texas 77030, USA.

Accepted 12 March_1979
1974; Lavyne et al., 1975; Lust et al., 1975; Welch et al., 1977; Gaudet et al., 1978) and middle cerebral artery (MCA) occlusion in the squirrel monkey (Zervas et al., 1974) resulted in depletion of 5-HT, dopamine (DA), and noradrenaline (NE) in the cerebral cortex, although there is evidence that, in the gerbil, seizures contributed to the catecholamine depletion (Welch et al., 1978). On the other hand, ischaemia produced by cerebral embolism caused rapid depletion of NE but increase of DA in rat cerebral cortex (Kogure et al., 1975). There is evidence, therefore, that brain monoamine changes may depend in part on the method by which ischaemia is induced, the effects of embolism differing from those of permanent surgical vascular occlusion. This is debatable since relatively few studies have concentrated on the effects of cerebral embolism. Development of the Microfil embolism technique (Molinari et al., 1974) prompted this study of cerebral embolism in the primate and the effect on monoamine metabolism. 


\section{Methods}

Seventeen baboons (Papio anubis) weighing 5$10 \mathrm{~kg}$ were anaesthetised with intravenous pentobarbitone $(25 \mathrm{mg} / \mathrm{kg})$. After tracheostomy, the animals were immobilised by $0.1 \mathrm{mg} / \mathrm{kg}$ body weight of pancuronium bromide (Pavulon), and anaesthesia was maintained by inhalation of $20 \%$ nitrous oxide in $20 \%$ oxygen using a Harvard variable speed respirator. Endtidal $\mathrm{CO}_{2}$ was recorded continuously with a Beckman infrared gas analyser. A catheter was inserted through the femoral artery into the descending aorta to monitor systemic blood pressure. Two catheters were inserted into the femoral veins, one to permit continuous intravenous infusion of isotonic saline at a rate sufficient to maintain mean arterial blood pressure (MABP) constant, and another for the return of blood drawn via a catheter in the left brachial artery into an extracorporeal circulation system (see below).

A midline cervical incision was made and neck dissection was performed. A catheter was inserted via the left lingual artery to permit intracarotid injection of $1.5 \mathrm{ml}$ boluses of hydrogen-saturated saline for measurement of hemispheric blood flow (HBF). Another catheter was inserted into the left lateral sinus via the facial vein to draw cerebral venous blood into an extracorporeal circulation. A specially made T-shaped catheter was inserted into the left CCA to permit the injection of Microfil emboli without interruption of carotid blood flow. The left external carotid artery was ligated, and the vagus nerve and cervical sympathetic chains were preserved during these surgical procedures.

The extracorporeal system included a Guyton analyser for measuring cerebral arteriovenous (A-V) oxygen differences as well as oxygen and hydrogen electrodes mounted in flow-through cuvettes for measuring the partial pressure of oxygen $\left(\mathrm{PvjO}_{2}\right)$ and hydrogen $\left(\mathrm{pH}_{2}\right)$ in jugular venous blood (Gotoh et al., 1966). Arterial and cerebral venous blood were propelled at $5 \mathrm{ml} / \mathrm{min}$ through the cuvette system and the Guyton (A-V) oxygen analyser and returned to the systemic circulation via the femoral vein. Heparin (3000 IU) was injected intravenously before the extracorporeal circulation pump was started.

Arterial blood $\mathrm{PO}_{2}, \mathrm{PCO}_{2}$, and $\mathrm{pH}$ were checked frequently with a Corning 165 blood gas analyser. The EEG and ECG were recorded throughout the experiment with a Grass 4 channel electroencephalograph.

The animals were divided into two experimental groups: (1) a sham-operated control group, and (2) a group with acute embolisation. Cerebral emboli were prepared according to a modification of the method originally described by Molinari et al. (1974). First the left carotid artery was injected with 20 particles of Microfil, $1.4 \mathrm{~mm}$ in diameter and $1.0 \mathrm{~mm}$ in length, to produce multiple cerebral ischaemic foci in the left hemisphere. Immediately after this, a single cylindrical embolus, $7 \mathrm{~mm}$ in length and $1.6 \mathrm{~mm}$ in diameter, was injected through the same catheter into the left carotid artery, to produce selective segmental occlusion of the trunk of the left MCA. The localisation of cerebral emboli was confirmed by necropsy examination of the brain sections.

Hemisphere blood flow was measured, before and after embolisation, from the clearance curves of hydrogen produced by intracarotid injection of a bolus of hydrogen-saturated saline, recorded by means of a cuvette monitored hydrogen electrode, and calculated by stochastic analysis (Shinohara et al., 1969).

Cisternal puncture was performed and $3 \mathrm{ml}$ of cerebrospinal fluid (CSF) were withdrawn, first in the steady state and again at the end of the study, for determination of CSF levels of homovanillic acid (HVA) and 5-hydroxyindoleacetic acid (5HIAA). At the end of the experiment the animals were killed; the brains were removed and dissected in the cold. Tissue samples were taken from different brain regions and frozen in liquid nitrogen for later assay of NE, DA, and 5-HT.

For this purpose, the samples were homogenised in $0.4 \mathrm{M}$ perchloric acid. Catecholamines were extracted from the tissue homogenate on activated alumina at $\mathrm{pH}$ 8.6. After organic extraction from the column effluent, 5-HT was assayed fluorometrically using the methods of Curzon and Green (1970) and Maickel and Miller (1966). Catecholamines were eluted from the alumina columns with $5 \mathrm{ml}$ of $0.2 \mathrm{M}$ acetic acid. The eluate from the alumina was brought to $\mathrm{pH} 6.0$, placed on amberlite (CG $50\left[\mathrm{Na}^{+}\right]$form) columns and eluted with $2 / 3 \mathrm{M}$ boric acid. Noradrenaline in the eluate was analysed fluorometrically using the trihydroxyindole reaction according to the methods of Renzini et al. (1970) and Valori et al. (1970). Dopamine was analysed fluorometrically according to the methods of Carlsson and Waldeck (1958) and Anton and Sayre (1964).

Extraction of HVA and 5-HIAA from CSF was by a combination of the methods of Ashcroft et al. (1968) and Gerbode and Bowers (1968). Both compounds were assayed fluorometrically, 5-HIAA by the technique of Ashcroft and Sharman (1962) 
and HVA according to Curzon et al. (1970).

An Aminco-Bowman spectrophotofluorometer equipped with an $\mathrm{X}-\mathrm{Y}$ plotter was used for all measurements. Recovery and reproducibility data for the above methodologies have been published in a previous report (Welch et al., 1977). All statistical analyses were performed using Student's $t$ test.

\section{Results}

Embolisation was successful in nine baboons. The site of embolisation in the proximal portion of the left MCA was confirmed by localising the cylindrical embolus which obstructed the main trunk of the MCA from its own origin to the origin of the orbitofrontal artery. All experiments in which the embolus was located just inside the internal carotid artery (ICA) or distal to the origin of the orbitof rontal artery were discarded. The orbitofrontal artery, which arises from the main trunk of the MCA approximately $10 \mathrm{~mm}$ distal to its origin from the internal carotid artery, divides into cortical branches and a large group of lateral lenticulostriate arteries. The cortical branches supply most of the orbital surface of the frontal lobe and have rich leptomeningeal anastomoses with the branch of the anterior cerebral artery (ACA). The large group of lateral lenticulostriate arteries supplies the corpus striatum, the lateral division of the globus pallidus, the claustrum, and the internal and external capsule (Watanabe et al., 1977). The smaller emboli were predominantly located in white and grey matter throughout the left hemisphere. Rarely, one or two microemboli had passed via the circle of Willis to the right hemisphere.
EFFECT OF EMBOLISATION ON BLOOD FLOW AND OXYGEN METABOLISM

Hemispheric blood flow and metabolism measurements in the ipsilateral hemisphere before and after acute Microfil embolisation are shown in Table 1.

Immediately after embolisation $\mathrm{HBF}$ showed a small but significant decrease, but after 60 minutes there was a more marked reduction. Cerebral metabolic rate for oxygen $\left(\mathrm{CMRO}_{2}\right)$ also became significantly reduced. There was either flattening or profound slowing of EEG activity in the embolised hemisphere: MABP and $\mathrm{PCO}_{2}$ were unchanged.

\section{EFFECT OF EMBOLISATION ON BRAIN MONOAMINES}

Dopamine levels became increased in cortical grey matter 60 minutes after unilateral MCA embolisation. The increases were significant in frontal and occipital regions, but not in the parietal or temporal cortex (Table 2). Of the basal ganglia measurements, reduction of DA was observed only in the ipsilateral caudate nucleus. Noradrenaline levels were markedly increased to an equal degree in grey matter from both cerebral hemispheres, as well as in subcortical structures bilaterally (Table 3). Brain 5-HT levels were unchanged after cerebral embolisation.

Levels of 5-HIAA became significantly increased in cisternal CSF 60 minutes after unilateral MCA embolisation (Figure) but HVA levels were unchanged.

\section{Discussion}

EFFECT OF MICROFIL EMBOLISM ON CEREBRAL HAEMODYNAMICS

The reduction of $\mathrm{HBF}$ after MCA embolisation

Table 1 Cerebral blood flow and metabolism in acute cerebral embolisation*

\begin{tabular}{|c|c|c|c|}
\hline & \multicolumn{3}{|c|}{ Time relative to embolisation } \\
\hline & Before & Immediately after & 60 minutes after \\
\hline CBF (nll $/ 100 \mathrm{~g} / \mathrm{min})$ & $\begin{array}{c}36.5 \pm 1.4 \\
(9)\end{array}$ & $\begin{array}{l}34.9 \pm 1.3 \dagger \\
\quad(9)\end{array}$ & $\begin{array}{l}29.7 \pm 1.6 \ddagger \\
(8)\end{array}$ \\
\hline $\mathrm{CMRO}_{2}(\mathrm{ml} / 100 \mathrm{~g} / \mathrm{min})$ & $\begin{array}{c}2.40 \pm 0.16 \\
(7)\end{array}$ & $\begin{array}{c}1.88 \pm 0.23 \dagger \\
(6)\end{array}$ & $\begin{array}{l}1.97 \pm 0.17 \ddagger \\
\quad \text { (7) }\end{array}$ \\
\hline $\mathrm{PvjO}_{2}$ & $\begin{array}{c}45.5 \pm 2.2 \\
(7)\end{array}$ & $\begin{array}{c}43.1 \pm 1.0 \\
(3)\end{array}$ & $\begin{array}{c}42.4 \pm 4.2 \\
\text { (7) }\end{array}$ \\
\hline MABP (mmHg) & $\begin{array}{c}97.3 \pm 4.3 \\
(8)\end{array}$ & $\begin{array}{c}89.4 \pm 1.0 \\
(8)\end{array}$ & $\begin{array}{c}95.5 \pm 3.2 \\
(8)\end{array}$ \\
\hline $\mathrm{PCO}_{2}(\mathrm{mmHg})$ & $\begin{array}{c}41.1 \pm 0.9 \\
(8)\end{array}$ & - & $\begin{array}{c}41.7 \pm 1.2 \\
(8)\end{array}$ \\
\hline
\end{tabular}

*Values are mean \pm standard error.

†Statistically significant from steady state, $\mathrm{P}<0.05$, on paired $t$ test.

† Statistically significant from steady state, $P<0.01$, on paired $t$ test.

( ) Indicates number of observations. 
Table 2 Brain dopamine levels 60 minutes after embolisation compared with controls

\begin{tabular}{|c|c|c|c|}
\hline \multirow[t]{3}{*}{ Brain region } & \multicolumn{3}{|l|}{ Dopamine $\mu \mathrm{g} / \mathrm{g}^{*}$} \\
\hline & \multirow[t]{2}{*}{$\begin{array}{l}\text { Sham-operated group } \dagger \\
\text { (6) }\end{array}$} & \multicolumn{2}{|c|}{$\begin{array}{l}\text { MCA embolisation group } \\
\text { (9) }\end{array}$} \\
\hline & & Left & Right \\
\hline $\begin{array}{l}\text { Frontal } \\
\text { Temporal } \\
\text { Parietal } \\
\text { Occipital } \\
\text { Caudate nucleus } \\
\text { Putamen } \\
\text { Globus pallidus } \\
\text { Thalamus }\end{array}$ & $\begin{array}{c}0.11 \pm 0.01 \\
0.06 \pm 0.01 \\
0.09 \pm 0.01 \\
0.04 \pm 0.01 \\
10.40 \pm 0.55 \\
9.16 \pm 0.43 \\
3.07 \pm 1.01 \\
0.92 \pm 0.48\end{array}$ & $\begin{array}{l}0.24 \pm 0.06 \ddagger \\
0.21 \pm 0.05 \\
0.18 \pm 0.04 \\
0.18 \pm 0.03 \S \\
6.83 \pm 0.83 \S \\
8.67 \pm 1.18 \\
2.25 \pm 0.58 \\
0.70 \pm 0.29\end{array}$ & $\begin{array}{l}0.21 \pm 0.0{ }_{+}^{+} \\
0.23 \pm 0.05 \\
0.19 \pm 0.07 \\
0.16 \pm 0.04 \ddagger \\
7.03 \pm 1.43 \\
8.85 \pm 0.84 \\
2.08 \pm 0.37 \\
0.65 \pm 0.21\end{array}$ \\
\hline
\end{tabular}

*Values are mean \pm standard error.

+ Values from both hemispheres were pooled.

† Statistically significant from sham-operated values, $\mathrm{P}<0.05$.

$\S$ Statistically significant from sham-operated values, $P<0.01$.

( ) indicates number of measurements.

Table 3 Brain noradrenaline levels 60 minutes after embolisation compared with controls

\begin{tabular}{|c|c|c|c|}
\hline \multirow[t]{3}{*}{ Brain region } & \multicolumn{3}{|l|}{ Noradrenaline $\mu \mathrm{g} / \mathrm{g}^{*}$} \\
\hline & \multirow[t]{2}{*}{$\begin{array}{l}\text { Sham-operated group } \dagger \\
\text { (6) }\end{array}$} & \multicolumn{2}{|c|}{$\begin{array}{l}\text { MCA embolisation group } \\
\text { (9) }\end{array}$} \\
\hline & & Left & Right \\
\hline $\begin{array}{l}\text { Frontal } \\
\text { Temporal } \\
\text { Parietal } \\
\text { Occipital } \\
\text { Caudate nucleus } \\
\text { Putamen } \\
\text { Globus pallidus } \\
\text { Thalamus }\end{array}$ & $\begin{array}{l}0.09 \pm 0.02 \\
0.07 \pm 0.01 \\
0.14 \pm 0.01 \\
0.07 \pm 0.01 \\
0.20 \pm 0.03 \\
0.17 \pm 0.02 \\
0.19 \pm 0.03 \\
0.35 \pm 0.07\end{array}$ & $\begin{array}{l}1.22 \pm 0.41 \ddagger \\
1.39 \pm 0.48+ \\
1.48 \pm 0.28 \\
1.40 \pm 0.50 \\
1.16 \pm 0.24 \S \\
1.30 \pm 0.29 \$ \\
1.76 \pm 0.77 \\
1.21 \pm 0.29 \ddagger\end{array}$ & $\begin{array}{l}1.24 \pm 0.38 \ddagger \\
1.19 \pm 0.39 \ddagger \\
1.33 \pm 0.27 \ddagger \\
1.22 \pm 0.38_{\ddagger}^{\ddagger} \\
1.20 \pm 0.29 \ddagger \\
1.46 \pm 0.30 \$ \\
2.44 \pm 0.96 \\
1.35 \pm 0.37_{\ddagger}^{+}\end{array}$ \\
\hline
\end{tabular}

*Values are mean \pm standard error.

†Values from both hemispheres are pooled.

¥Statistically significant from sham-operated values, $\mathrm{P}<0.05$.

§Statistically significant from sham-operated values, $\mathrm{P}<0.01$.

( ) Indicates number of measurements.

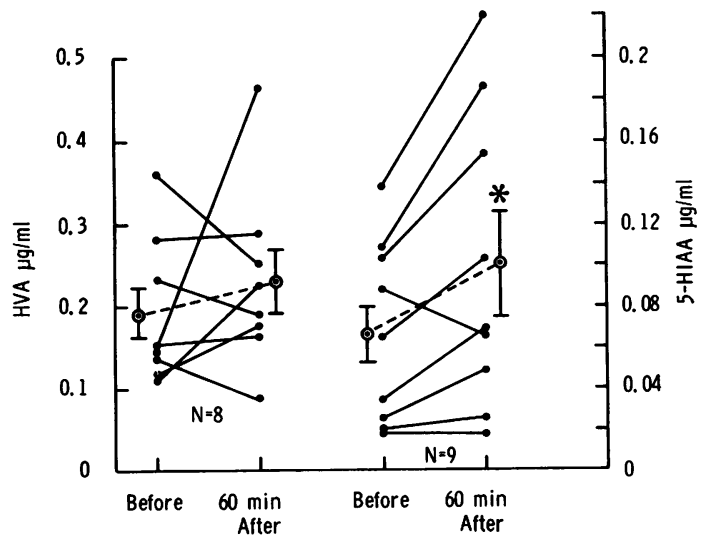

Figure The effect of cerebral embolisation on cisternal CSF HVA and 5-HIAA values before and 60 minutes after embolisation in the baboon.

$*=$ significant difference on paired $t$ test,

$\stackrel{T}{\Gamma}=$ mean $\pm S E$. was small compared to that found after surgical occlusion of the MCA (Reivich et al., 1974; Symon et al., 1974). Morphological study of the Microfil embolism model has shown fairly consistent infarction of the caudate nucleus, putamen, globus pallidus, and internal capsule, with relative sparing of the cerebral cortex because of the extreme abundance of leptomeningeal anastomoses between the ACA, MCA, and posterior cerebral artery (Molinari et al., 1974; Watanabe et al., 1977). Therefore, a rich collateral circulation may become established rapidly after cerebral embolisation. After surgical occlusion of the MCA, collateral circulation develops more slowly and less completely (Denny-Brown and Meyer, 1957; Meyer et al., 1962).

Immediately after cerebral embolisation, however, the distribution of hydrogen to the ipsilateral hemisphere and the ipsilateral transverse sinus may be altered so that the hydrogen clearance method 
used may underestimate early flow reduction. The small HBF reduction 60 minutes after embolisation could be the result of depressed energy metabolism as indicated by the low $\mathrm{CMRO}_{2}$.

\section{EFFECT OF EMBOLISM ON BRAIN MONOAMINES}

Cerebral ischaemia and infarction on permanent occlusion of a major cerebral artery eventually depletes brain catecholamines (Zervas et al., 1974; Lavyne et al., 1975; Lust et al., 1975; Welch et al., 1977; Gaudet et al., 1978). The fall of dopamine in the caudate nucleus ipsilateral to the embolism agrees with these studies since this structure is consistently infarcted after proximal MCA occlusion. On the other hand, dopamine was increased in certain cortical regions after embolism. Microembolic occlusion of the cerebral microvasculature is followed by disruption or onward displacement of some of the emboli, causing scattered foci of ischaemia along with foci in which reperfusion of previously ischaemic brain has taken place. A recent study in the gerbil has shown that catecholamine levels become markedly raised during cerebral reperfusion in the early post-ischaemic period after transient cerebral ischaemia (Gaudet et al., 1978). Such events, following on from the first injection of multiple small emboli, could be one of the possible explanations for the DA increase measured in this experiment. (Although there was reduction of total hemispheric blood flow, this does not exclude the existence of regions of increased flow, due either to collateral circulation or to reactive hyperaemia. Measurement of regional cerebral blood flow necessary to clarify this was not carried out.) Increase of DA was less significant in brain regions supplied by the MCA, possibly because these areas were poorly perfused since the main trunk of the MCA was permanently occluded by the large embolus.

Of the changes in monoamines measured after cerebral embolism, those of noradrenaline (NE) were the most striking. Large bilateral increases were measured in both cortical and subcortical structures, suggesting altered metabolism throughout the ascending noradrenergic tracts. Similar changes in NE relative to DA were found during cerebral reperfusion after transient unilateral hemispheric ischaemia in the gerbil; massive bilateral increases in cortical NE levels were measured, as a similar, though less marked increase in DA. This has been termed "catecholamine rebound" and may represent a state of post-ischaemic hypermetabolism (Gaudet et al., 1978).

Bilateral changes in catecholamine levels after unilateral ischaemia have been found consistently in earlier studies from this laboratory using the gerbil model (Welch et al., 1977, 1978; Gaudet et al., 1978). The changes in the non-ischaemic hemisphere recorded in the present study could either be a cause or an effect of diaschisis-that is, a remote effect of a focal brain lesion on cerebral metabolism and function. Kogure et al. (1975) have also recorded bilateral changes in cortical NE levels after unilateral embolism in the rat and attributed this to synaptic release of NE after generalised neuronal depolarisation. Levy and Duffy (1977) also observed changes in cerebral energy metabolism in the contralateral cortex of gerbils with unilateral hemispheric ischaemia.

The absence of significant change in tissue 5-HT levels after embolism might suggest that metabolism of this monoamine was unaltered. However, 5-HIAA, the breakdown product of 5-HT, was increased in the CSF. The results suggest increased 5-HT catabolism and compensatory increased synthesis (Welch et al., 1972) and that impaired removal of 5-HIAA from the CSF sink seems a less likely explanation as HVA would be comparably affected. The inconsistency of change in CSF levels of HVA after embolism matches the variable findings in DA levels-that is, depletion in the caudate nucleus and increase in cortical regions.

The biochemical mechanisms underlying the monoamine changes during ischaemia are unknown and could not be studied appropriately in this model. Dopamine and noradrenaline have been shown to inhibit cortical neurones (Krnjevi and Phillis, 1963; Stone and Taylor, 1977). The increase of cortical catecholamine levels could, therefore, have caused depression of neuronal function (indicated by slowing and flattening of the EEG) leading to a secondary decrease in cortical blood flow and oxygen consumption. However, although whole hemisphere blood flow and metabolism were depressed, the possibility of regional differences cannot be ignored. Fieschi et al. (1978) have identified scattered foci of increased 2-deoxyglucose metabolism after cerebral embolism. This could result from increased catecholamine levels in the same brain areas since cerebral energy metabolism is influenced by central adrenergic activity (Estler and Ammon, 1966; Leonard, 1971). In support of this, Levy and Duffy (1977) recorded a post-ischaemic increase of cerebral energy metabolism, which was delayed compared to the time of maximal post-ischaemic catecholamine increase measured in the same gerbil model used in our laboratory. 
In conclusion, the effects of cerebral embolism on brain monoamine metabolism appear to be different from the effects of permanent surgical occlusion of major cerebral vessels, probably because of the differing haemodynamic changes induced by each technique. However, as monoamine findings after embolism in the baboon differ from those after cerebral embolism in the rat (Kogure et al., 1975), a species variability in response may also exist. The relevance of the monoamine changes to the progression of cerebral ischaemia and the complications associated with cerebral embolism remain to be established.

This work was supported by grant NS 09287 from the National Institute of Neurological and Communicative Disorders and Stroke, National Institutes of Health, Bethesda, Maryland, USA.

\section{References}

Anton, A. H., and Sayre, D. F. (1964). The distribution of dopamine and dopa in various animals and a method for their determination in diverse biological material. Journal of Pharmacology and Experimental Therapeutics, 145, 326-336.

Ashcroft, G. W., and Sharman, D. F. (1962). Druginduced changes in the concentration of 5-OR indolyl compounds in cerebrospinal fluid and caudate nucleus. British Journal of Pharmacology and Chemotherapy, 19, 153-160.

Ashcroft, G. W., Crawford, T. B. B., Dow, R. C., and Guldberg, H. C. (1968). Homovanillic acid, 3, 4dihydroxyphenylacetic acid and 5-hydroxy-3indoleacetic acid in serial samples of cerebrospinal fluid from the lateral ventricle of the dog. British Journal of Pharmacology and Chemotherapy, 33, 441-456.

Carlsson, A., and Waldeck, B. (1958). A fluorimetric method for the determination of dopamine (3hydroxytyramine). Acta Physiologica Scandinavica, 44, 293-298.

Curzon, G., and Green, A. R. (1970). Rapid method for the determination of 5-hydroxytryptamine and 5 -hydroxyindoleacetic acid in small regions of rat brain. British Journal of Pharmacology, 39, 653-655.

Curzon, G., Godwin-Austen, R. B., Tomlinson, E. B., and Kantamaneni, B. D. (1970). The cerebrospinal fluid homovanillic acid concentration in patients with Parkinsonism treated with L-dopa. Journal of Neurology, Neurosurgery, and Psychiatry, 33, 1-6.

Denny-Brown, D., and Meyer, J. S. (1957). The cerebral collateral circulation. 2. Production of cerebral infarction by ischaemic anoxia and the reversibility of early stages. Neurology (Minneapolis), 7, 567579.

Estler, C. J., and Ammon, H. P. T. (1966). The influence of the $\beta$-sympathicolytic agent propranolol on glycogenolysis and glycolysis in muscle, brain and liver of white mice. Biochemical Pharmacology, 15, 2031-2035.

Fieschi, C., Sakurada, O., and Sokoloff, L. (1978). Local cerebral glucose utilisation following experimental TIAs in the rabbit. In Advances in Neurology, volume 20. Edited by J. Cervós-Navarro, E. Betz, G. Ebhart, R. Ferszt, and R. Wullenweber. Raven Press: New York.

Gaudet, R., Welch, K. M. A., Chabi, E., and Wang, T-P. (1978). Effect of transient ischemia on monoamine levels in the cerebral cortex of gerbils. Journal of Neurochemistry, 30, 751-757.

Gerbode, F. A., and Bowers, M. B. (1968). Measurement of acid monoamine metabolites in human and animal cerebrospinal fluid. Journal of Neurochemistry, 15, 1053-1055.

Gotoh, F., Meyer, J. S., and Ebihara, S. (1966). Continuous recording of human cerebral blood flow and metabolism. Methods for electronic monitoring of arterial and venous gases and electrolytes. Medical Research and Engineering, 5, 13-19.

Kogure, K., Scheinberg, P., Matsumoto, A., Busto, R., and Reinmuth, O. M. (1975). Catecholamines in experimental brain ischemia. Archives of Neurology (Chicago), 32, 21-24.

Krnjević, K., and Phillis, J. W. (1963). Actions of certain amines on cerebral cortical neurones. British Journal of Pharmacology and Chemotherapy, 20, 471-490.

Lavyne, M. H., Moskowitz, M. A., Larin, F., Zervas, N. T., and Wurtman, R. J. (1975). Brain $\mathrm{H}^{3}-8$ catecholamine metabolism in experimental cerebralo ischemia. Neurology (Minneapolis), 25, 483-485.

Leonard, B. E. (1971). The effect of some alphaadrenergic receptor blocking drugs on carbohydrate metabolism in mouse brain. Neuropharmacology, 28, 63-70.

Levy, D. E., and Duffy, T. E. (1977). Cerebral energy metabolism during transient ischemia and recovery in the gerbil. Journal of Neurochemistry, 28, 63-70.

Lust, W. D., Mršulja, B. B., Mršulja, B. J., Passonneau, J. V., and Klatzo, I. (1975). Putative neurotransmitters and cyclic nucleotides in prolonged ischemia of the cerebral cortex. Brain Research, 98, 394-399.

Maickel, R. P., and Miller, F. P. (1966). Fluorescent products formed by reaction of indole derivatives and o-phthaldialdehyde. Analytical Chemistry, 38, 1937-1938.

Meyer, J. S., Gotoh, F., and Tazaki, Y. (1962). Circulation and metabolism following experimental cerebral embolism. Journal of Neuropathology and Experimental Neurology, 21, 4-24.

Molinari, G. S., Moseley, J. I., and Laurent, J. P. (1974). Segmental middle cerebral artery occlusion in primates: An experimental method requiring minimal surgery and anesthesia. Stroke, 5, 334339.

Reivich, M., Kassell, N. F., and Sano, N. (1974). 
Cerebral hemodynamic and metabolic alterations in an acute stroke model in the baboon. In Cerebral Vascular Disease, pp. 75-84. Edited by J. S. Meyer, H. Lechner, M. Reivich, and O. Eichhorn. Georg Thieme Verlag: Stuttgart.

Renzini, V., Brunori, C. A., and Valori, C. (1970). A sensitive and specific fluorimetric method for the determination of noradrenalin and adrenalin in human plasma. Clinica Chimica Acta, 30, 587-594.

Shinohara, Y., Meyer, J. S., Kitamura, A., Toyoda, M., and Ryu, T. (1969). Measurement of cerebral hemispheric blood flow by intracarotid injection of hydrogen gas. Validation of the method in the monkey. Circulation Research, 25, 735-745.

Stone, T. W., and Taylor, D. A. (1977). Microiontophoretic studies of the effects of cyclic nucleotides on excitability of neurones in the rat cerebral cortex. Journal of Physiology, 266, 523-543.

Symon, L., Pasztor, E., and Branston, N. M. (1974). The distribution and density of reduced cerebral blood flow following acute middle cerebral artery occlusion: an experimental study by the technique of hydrogen clearance in baboons. Stroke, 5, 355364.

Valori, C., Brunori, C. A., Renzini, V., and Corea, L. (1970). Improved procedure for formation of epinephrine and norepinephrine fluorophors by the trihydroxyindole reaction. Analytical Biochemistry,
33, 158-167.

Watanabe, O., Bremer, A. M., and West, C. R. (1977). Experimental regional cerebral ischemia in the middle cerebral artery territory in primates. Part 1. Angio-anatomy and description of an experimental model with selective embolization of the internal carotid artery bifurcation. Stroke, 8, 61-70.

Welch, K. M. A., Meyer, J. S., Teraura, T., Hashi, K., and Shinmaru, S. (1972). Ischaemic anoxia and cerebral serotonin levels. Journal of the Neurological Sciences, 16, 85 -92.

Welch, K. M. A., Hashi, K., and Meyer, J. S. (1973). Cerebrovascular response to intracarotid injection of serotonin before and after middle cerebral artery occlusion. Journal of Neurology, Neurosurgery, and Psychiatry, 36, 724-735.

Welch, K. M. A., Chabi, E., Buckingham, J., Bergin, B., Achar, V. S., and Meyer, J. S. (1977). Catecholamine and 5-hydroxytryptamine levels in ischemic brain: influence of p-chlorophenylalanine. Stroke, 8, 341-346.

Welch, K. M. A., Wang, T-P. F., and Chabi, E. (1978). Ischemia-induced seizures and cortical monoamine levels. Annals of Neurology, 3, 152-155.

Zervas, N. T., Hori, H., Negora, M., Wurtman, R. J., Larin, F., and Lavyne, M. A. (1974). Reduction in brain dopamine following experimental cerebral ischemia. Nature, 247, 283-284. 